\title{
The National Ignition Facility Project: An Update
}

\author{
W.J. Hogan, E. Moses, B. Warner, M. Sorem, J. Soures, \\ and $\mathrm{J}$. Hands
}

This article was submitted to the

$14^{\text {th }}$ Topical Meeting on the Technology of Fusion Energy, Park City, UT, October $15-19,2000$

\section{December 7, 2000}

U.S. Department of Energy

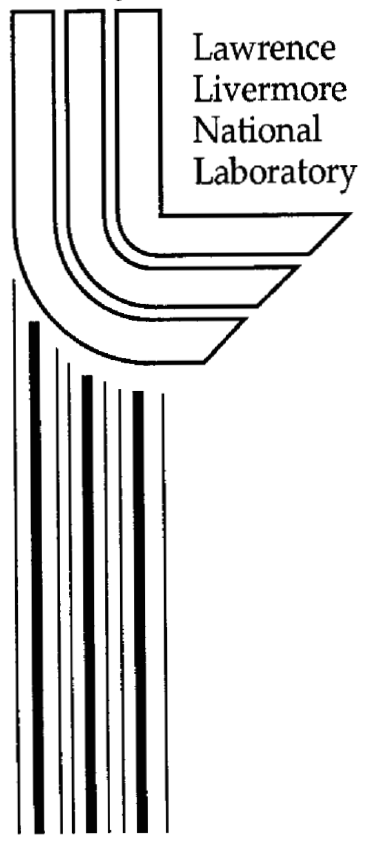




\section{DISCLAIMER}

This document was prepared as an account of work sponsored by an agency of the United States Government. Neither the United States Government nor the University of California nor any of their employees, makes any warranty, express or implied, or assumes any legal liability or responsibility for the accuracy, completeness, or usefulness of any information, apparatus, product, or process disclosed, or represents that its use would not infringe privately owned rights. Reference herein to any specific commercial product, process, or service by trade name, trademark, manufacturer, or otherwise, does not necessarily constitute or imply its endorsement, recommendation, or favoring by the United States Government or the University of California. The views and opinions of authors expressed herein do not necessarily state or reflect those of the United States Government or the University of California, and shall not be used for advertising or product endorsement purposes.

This is a preprint of a paper intended for publication in a journal or proceedings. Since changes may be made before publication, this preprint is made available with the understanding that it will not be cited or reproduced without the permission of the author.

This report has been reproduced directly from the best available copy.

Available electronically at http://www.doc.gov/bridge

Available for a processing fee to U.S. Department of Energy

And its contractors in paper from

U.S. Department of Energy

Office of Scientific and Technical Information

P.O. Box 62

Oak Ridge, TN 37831-0062

Telephone: (865) 576-8401

Facsimile: (865) 576-5728

E-mail: reports@adonis.osti.gov

Available for the sale to the public from

U.S. Department of Commerce

National Technical Information Service

5285 Port Royal Road

Springfield, VA 22161

Telephone: (800) 553-6847

Facsimile: (703) 605-6900

E-mail: orders@ntis.fedworld.gov

Online ordering: http:/ / www.ntis.gov/ordering.htm

\section{OR}

Lawrence Livermore National Laboratory

Technical Information Department's Digital Library

http: / / www.llnl.gov/tid/Library.html 


$\begin{array}{llllll}\text { W. J. Hogan } & \text { E. Moses } & \text { B. Warner } & \text { M. Sorem } & \text { J. Soures } & \text { J. Hands } \\ \text { LLNL } & \text { LLNL } & \text { LLNL } & \text { LANL } & \text { U. Rochester } & \text { Sandia } \\ \text { Livermore, CA } & \text { Livermore, CA } & \text { Livermore, CA } & \text { Los Alamos, NM } & \text { Rochester, NY } & \text { Albuquerque, NM } \\ (925) 422-1344 & (925) 423-9624 & (925) 422-9237 & (505) 667-9739 & (716) 275-3866 & (505) 895-7120\end{array}$

\section{ABSTRACT}

The National Ignition Facility (NIF) consists of 192 forty-centimeter-square laser beams and a 10 -m-diameter target chamber. Physical construction began in 1997. The Laser and Target Area Building and the Optics Assembly Building were the first major construction activities, and despite several unforeseen obstacles, the buildings are now 92\% complete and have been done on time and within cost. Prototype component development and testing has proceeded in parallel. Optics vendors have installed fullscale production lines and have done prototype production runs. The assembly and integration of the beampath infrastructure has been reconsidered and a new approach has been developed. This paper will discuss the status of the NIF project and the plans for completion. It will also include summary information on Laser MegaJoule (LMJ) provided by M. Andre, LMJ Project Director.

\section{INTRODUCTION}

The NIF is designed to deliver $1.8 \mathrm{MJ}$ and $500 \mathrm{TW}$ of $0.35-\mu \mathrm{m}$ laser light to indirectly or directly driven Inertial Confinement Fusion (ICF) targets. This will compress and heat them to ignition. NIF is a critical element of the DOE $s$ Stockpile Stewardship Program (SSP) and will also contribute significantly to fundamental fusion science and energy applications. NIF is being designed and built by a Lawrence Livermore National Laboratory-led team from Los Alamos National Laboratory, Sandia National Laboratories, the University of Rochester, and LLNL.

The NIF driver consists of 192 , forty-centimeter-square laser beams arranged in bundles of $4 \times 2$ beams, six bundles to a cluster, two clusters to a laser bay (Figure 1). The rebaselining of the NIF Project this past year has not caused changes in the mission, the physics specifications, or the fundamental engineering design of NIF $[1,2,3,4]$. What has changed is the manner by which the lasers are being assembled and the systems approach to risk mitigation processes that have been put into place.

\section{THE APPROACH TO NIF}

Scaling NOVA laser architecture and technology to NIF size would have resulted in a prohibitively large estimated cost (probably more than $\$ 10$ billion). The goal of reducing the estimated cost by an order of magnitude required breakthrough thinking on many fronts. Most importantly, since construction time for a facility of this scale is so long, it is important to incorporate into the construction project technological improvements as they occur in the R\&D laboratories. Otherwise, when NIF was completed, it would contain obsolete equipment.

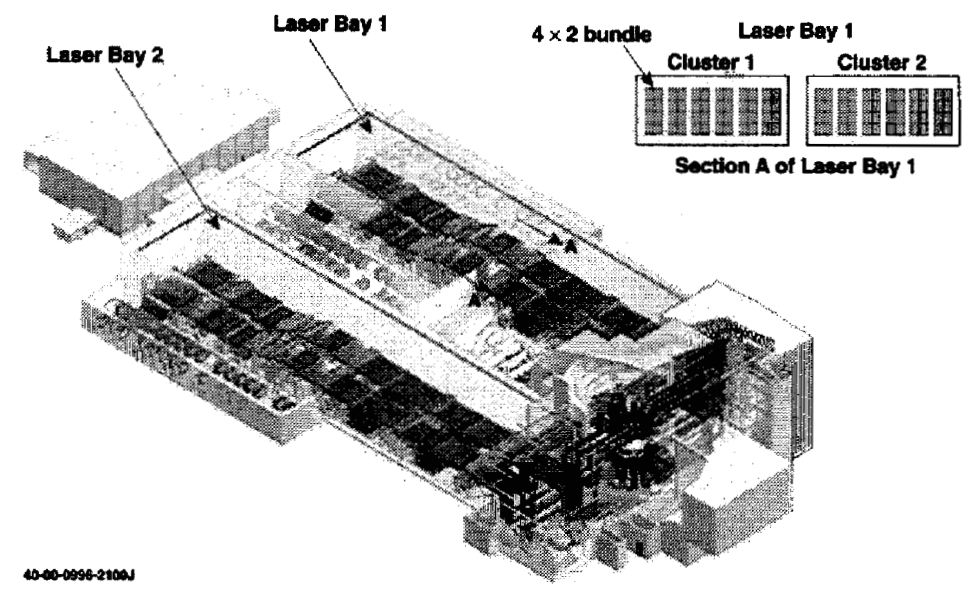

Figure 1. The NIF laser architecture groups 192 beamlines in 24 bundles of eight. 
A new (for large-aperture lasers) architecture was adopted that incorporated a multipass amplifier and high packing density. This new architecture concept was validated in a full-scale physics prototype of one beamline (Beamlet) in 1994 [5].

Mass production techniques were developed with industry for producing the more than 7500 large aperture optical components. The new optics manufacturing processes included, for example, continuous-pour manufacturing of $80 \times 40^{\circ} \mathrm{cm}$ laser glass slabs and rapid growth (couple of months instead of couple of years) of large $(>300 \mathrm{~kg})$ potassium dihydrogen phosphate (KDP) crystals.

Several major technology development programs were required to develop the large-aperture components that would make the new architecture possible. These included: (1) a large-aperture plasma electrode Pockels cell (PEPC) to switch the high-intensity beam into and out of the multipass amplifier cavity, (2) a servo-controlled deformable mirror in each beamline to correct the phase front for the inevitable optical distortions that occur, (3) a stable, high-gain Master Oscillator Room (MOR) and preamplifier, and (4) higher damage threshold optical components (at $1^{\circ} \mu \mathrm{m}$ and, for the final optics, at $0.35^{\circ} \mu \mathrm{m}$ ).

Many less exotic developments were also required to meet the cost goals. These included using an innovative set of management tools [6] for the construction of the conventional facilities (e.g., a Project Labor Agreement and Owner Controlled Insurance).

At this time, all the required manufacturing process and component development efforts have been successfully completed save one $(0.35-\mu \mathrm{m}$ damage), and that is on course for success by the time it is needed.

As the detailed design of NIF and the development of its components proceeded, attention increasingly focused on how the equipment would be assembled and integrated into an operational system. To put together the world $s$ largest optical instrument and have it operate reliably is a huge and tremendously complex undertaking. For example, there are about 300,000 parts in the main amplifier and 500,000 in the transport spatial filter system. More than 7500 large-aperture optical components and more than 15,000 smaller ones are needed. It gradually became clear that the effort and cost to assemble and integrate the components into an operating system would be larger than originally anticipated. Therefore, the Project team decided to alter the method of deploying NIF.

\section{REBASELINING NIF}

Plans for assembly and integration of the NIF special equipment have been dramatically revised. Industrial consultants and partners have helped develop a new method of accomplishment that better separates the conventional construction; beamline infrastructure installation and integration; beamline activation; and early experimental utilization of the facility. The NIF procurement strategy will emphasize procuring subsystems at a higher level of integration. The NIF will rely on industrial management of the major systems integration job. A new bottom-up roll up of estimated cost and schedule has been done by the Project and validated in independent reviews. The Department of Energy (DOE) has proposed this new NIF baseline plan to Congress.

The new NIF baseline path forward retains the original NIF mission, specifications, and design. The schedule is stretched by four years (two years due to Project issues and two years due to the DOE desire to limit early year supplemental funding so as to have a balanced SSP) to 2008 for the fully capable 192-beam facility. The new estimated NIF Total Project Cost for this stretched schedule is $\$ 2.249$ billion, including a $26 \%$ contingency on remaining activities, deemed appropriate by the independent review for this stage of a project.

\section{A. The NIF Deployment Plan}

Figure 2 illustrates the four major NIF systems: (1) conventional facilities, (2) beampath infrastructure, (3) line replaceable units (LRUs), and (4) optics. The conventional facilities include the site, buildings, and general utilities such as the HVAC system. The Beampath Infrastructure System (BIS) includes the mechanical beampath components (the large vacuum vessels at the ends of the spatial filters, the beam tubes, etc.) as well as the power systems support for all 192 beams. The LRUs are the mechanical modules that hold and position several optical components within the BIS. The optics are the laser slabs, crystal slices, lenses, and other optical components themselves.

The new deployment plan envisions completing the conventional facilities and installing, assembling, and integrating the BIS for all 192 beams before any LRUs are installed. The laser building is too large to make it a clean room as was done for Nova. Therefore, the BIS must be assembled in a relatively dirty environment, but its interior must be clean after installation. The optics are placed into the appropriate LRU in a clean room. Then the LRUs are inserted into their respective positions in the BIS. The second step of this process installing, assembling, and integrating the BIS into NIF will be done by Jacobs Engineering, a company with relevant experience. 
(a)

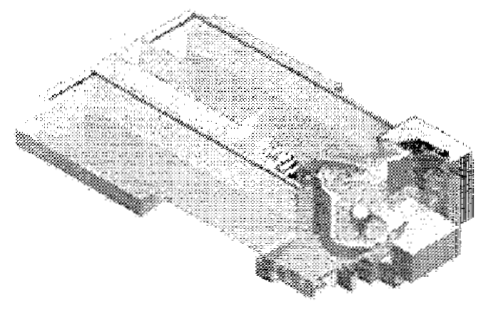

(c)

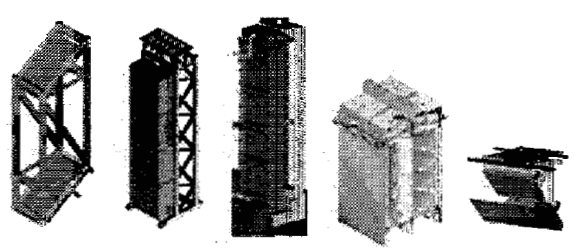

(b)

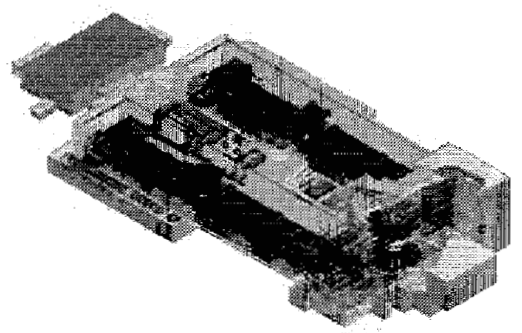

(d)

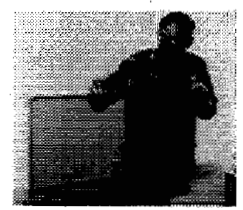

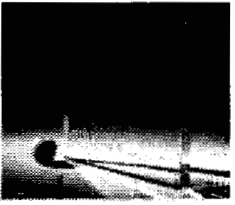

Figure 2. The NIF can be divided into four major systems: (a) Conventional facilities, (b) Infrastructure, (c) Line replaceable units, and (d) Optics.

\section{B. Progress on NIF}

1. Systems Engineering and Risk Mitigation. The systems engineering group in the NIF Project has established a risk control process to identify, characterize, evaluate, and then monitor and manage risk mitigation actions. This process has resulted in many small design or process changes that lower the likelihood of future problems. An illustrative example is the issue of aerosol clusters.

During development of NIF hardware, it was observed that aerosols are formed during each flashlamp pulse. Experiments showed that the source of the aerosols was the volatilization of organics left behind on surfaces after the usual cleaning and installation processes. The nanoscale particles formed coagulate into aerosol clusters up to $\sim 0.1^{\circ} \mathrm{mm}$ diameter. These can deposit on laser glass surfaces and create damage spots with the next laser shot. Systems analysis showed that, for the large size of NIF, this could have a serious impact on NIF availability and operations costs. Therefore, a new gas purge system was designed to flush the particulate clouds out of the amplifier between shots. Since the NIF design already planned recirculation of flashlamp cooling gas to meet the specified shot rate, only a small design change in the manifold allowed diverting $10 \%$ of the cooling gas to a filtered, recirculating gas system. This system will purge the main amplifier cavity of the aerosol clusters so that damage sites do not form from this source.

2. Construction Activities. During the rebaselining studies, NIF procurement and construction activities proceeded at full speed. Construction of the conventional facilities was a $\$ 270$ million subproject that is now $92 \%$ complete. Figure 3 a shows an aerial view of the Laser and Target Area Building (LTAB) and the attached Optics Assembly Building (OAB) as of April 2000. The roof is now complete. Beneficial occupancy has been established in the $\mathrm{OAB}$, and it is now being prepared for Class 100 assembly of NIF LRUs. In spite of several unforeseeable obstacles that could have had severe negative impacts on this construction activity (e.g., twice normal rainfall, mammoth bones and PCB bearing capacitors unearthed), the facilities are being completed on schedule and within the original estimated cost (including contingency).

The BIS includes many very large structures such as the vacuum vessels that form the ends of the spatial filters. Each vessel supports an entire cluster of 48 beamlines ( $4 \mathrm{X}$ 12 array). It also includes all the beam tubes that connect such vessels. Installing, assembling, and integrating the BIS requires making about 4500 clean connections in the relatively dirty environment of the LTAB. To do this job, the Project has signed a contract with Jacobs Engineering. This $\$ 230$ million Integration, Management and Installation (IMI) contract is the largest single NIF procurement.

The large BIS structures have been manufactured at shops around the country. They are then cleaned at a site near LLNL with high-pressure water with a surfactant wash. This is capable of removing surface particles to Level 80 and nonvolatile residues to $00.1 \mu \mathrm{g} / \mathrm{cm}^{2}$. These parts are then double wrapped to keep them clean and installed in the LTAB as part of the IMI contract. Figure $3 b$ shows eight of these large structures in place in one of the LTAB laser bays.

After installation of the mechanical hardware, the pulsed power system, gas cooling ducts, and control cabling will be installed. In recent off-site tests, full system operation $(\sim 2 \mathrm{MJ})$ of one module (capacitor to lamps) of the pulsed power system was completed successfully. Figure $3 \mathrm{c}$ shows what one of the laser bays will look like after installation of the complete BIS. To an observer in the laser bay, it might appear that the NIF was finished because it 
would not be possible to see that there were no optical components inside the BIS.

The ten-meter-diameter aluminum target chamber is in place and undergoing alignment checks (figure $3 \mathrm{~d}$ ). It has been vacuum leak checked and coated with a half meter of borated concrete. When the beam tubes and diagnostics are in place it will be very difficult to grasp the large size of this structure because so little of it will be visible at any one time.

3. Optics and Line Replaceable Units. Figure 4 shows the various LRUs that must be inserted into the BIS to activate individual $2 \times 4$ beam bundles. For ease of assembly and maintenance, most of these modules service either $4(1 \times 4)$ or $8(2 \times 4)$ adjacent beamlines.

As was mentioned earlier, development of new processes to mass produce the optical components has been very successful. Producing KDP and KD*P (the deuterated version) by the fast-growth method has exceeded expectations. Larger and more perfect crystals can be grown that yield more plates than expected. Pilot runs of laser glass have exceeded the yield goals of laser slabs that meet all specifications. These runs have now produced about $10 \%$ of the required laser slabs (Figure 5a). Altogether about $50 \%$ of the optical components have or are being produced. Production of large-aperture optical components that meet the cost, schedule, and performance goals was identified by nearly every one of the early external reviews as the greatest vulnerability for the NIF in terms of cost and schedule exposure. Many brand new

(a)

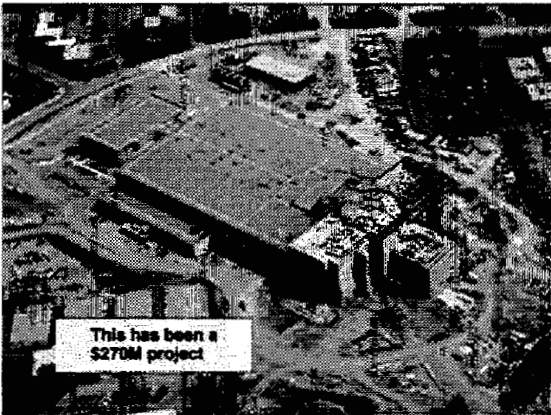

(c)

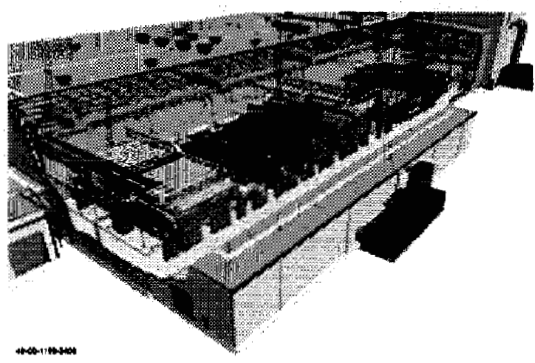

processes had to be developed, and it was not expected that all the development programs would succeed. Therefore, back-up processes were developed also. Virtually every one of these development programs has exceeded expectations.

The principal unresolved technical issue is the lifetime of some of the components in the final optics assembly (FOA) for each beamline (Figure 5b). Each FOA contains frequency conversion crystals that convert the infrared laser pulse into ultraviolet (UV), a wedged lens that focuses the pulse onto the target and separates the unconverted light from the main beam, a phase plate for beam smoothing, and a debris shield. Each FOA handles four beams. The goal for the NIF is to have these components routinely $(>1000$ shots) survive $8 \mathrm{~J} / \mathrm{cm}^{2}$ of UV light. At present, it has only been demonstrated that these optics have this long life at $4^{\circ} \mathrm{J} / \mathrm{cm}^{2}$. The existing technology can operate at $8 \mathrm{~J} / \mathrm{cm}^{2}$, but damage in some of the components is initiated at this level, and it grows with subsequent pulses so that those components must be removed and refurbished after about 100 shots. This would increase the operational costs. Therefore the effort to understand this issue and develop final optics that can have a longer lifetime at the higher fluence has been expanded. This program is showing some very promising results with laser annealing of the damage sites initiated. Apparently the annealing stops growth of the damage. Since we do not yet understand the mechanisms underlying this improvement, the development effort will continue. The NIF will not need the higher performance final optics until late in the decade, and there is confidence in improving the situation by that time.

(b)

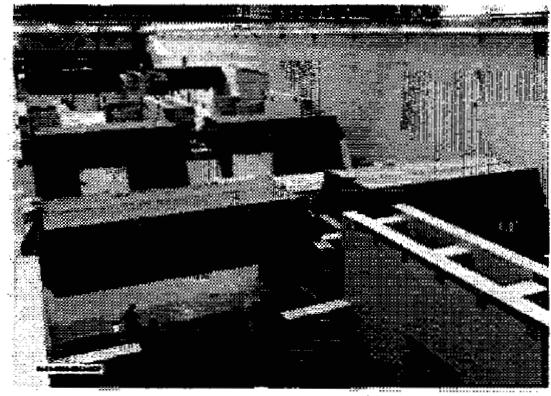

(d)

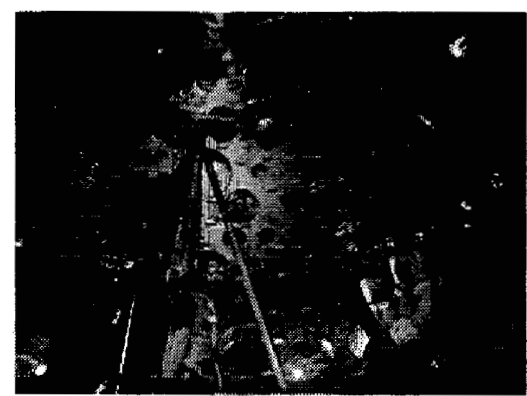

Figure 3. There has been much progress on NIF construction. (a) Conventional facilities are $92 \%$ complete, (b) Many of the large BIS structures have been installed, (c) Laser Bay after completion of BIS, (d) Target Chamber undergoing checks. 


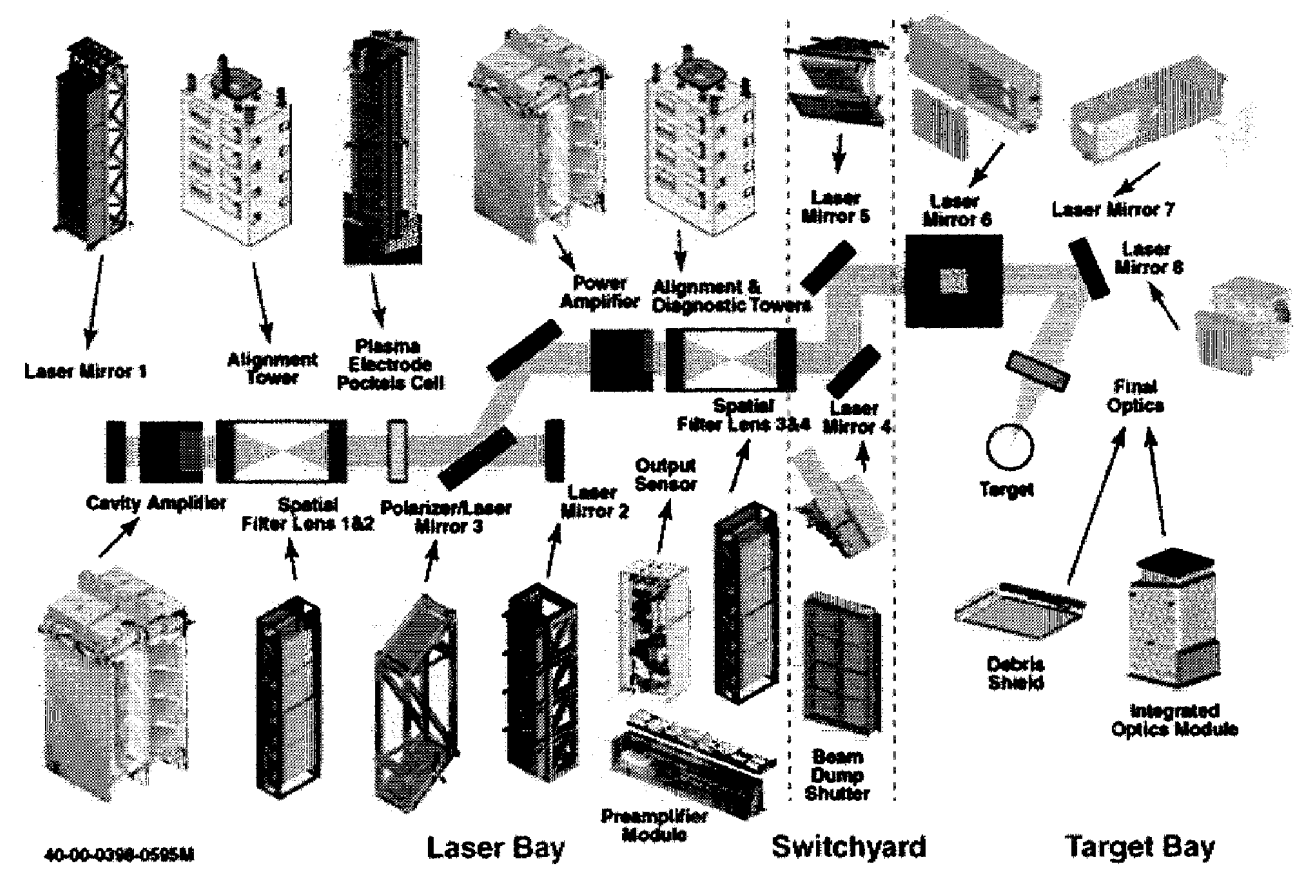

Figure 4. Line replaceable units (LRUs) contain the optical components and comprise the laser equipment

(a)

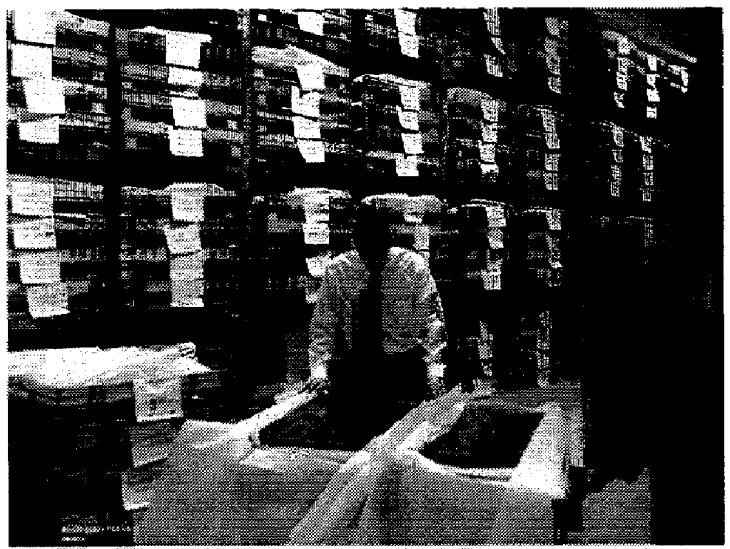

(c)

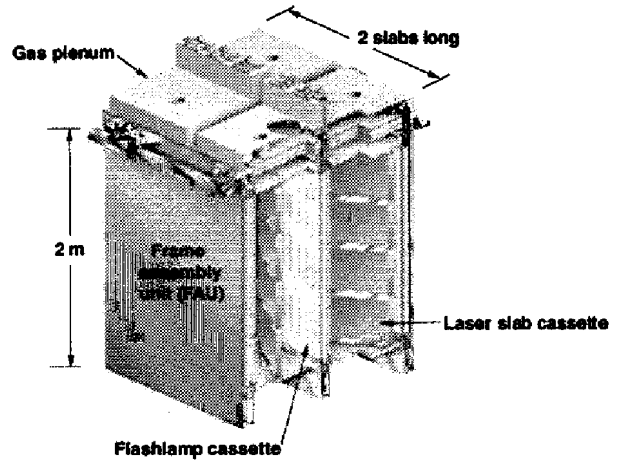

(b)

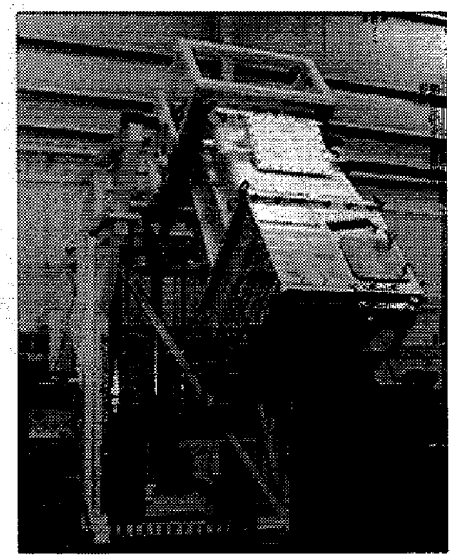

(d)

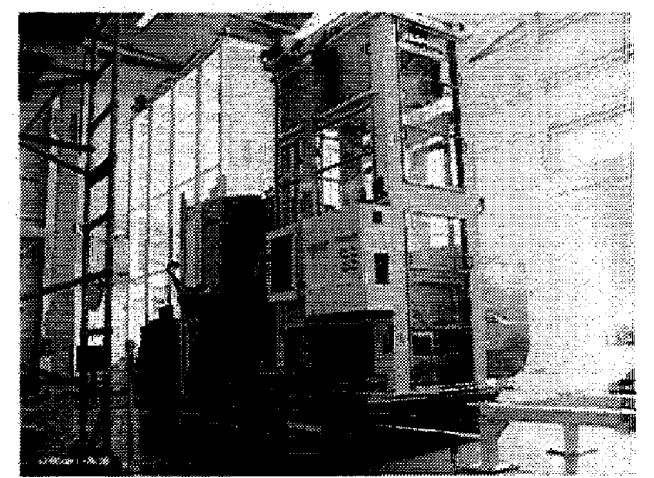

Figure 5. (a) Prototype production runs have produced $10 \%$ of the needed laser slabs, (b) The Final Optics Assembly focuses four beams onto the target, (c) The basic building block of the amplifier is a $4 \times 2 \times 2$ module, (d) The clean, robotic cart delivers and installs LRUs into the BIS. 
The basic building block of the NIF amplifier is a 4 $\mathrm{X} 2 \times 2$ module (Figure 5c). Assembling the Frame Assembly Unit (part of the BIS) in a clean room, packaging it, driving it around LLNL, installing it on mock-up of the situation in the LTAB, and then measuring its alignment has been successfully tested at full scale. Full-size prototype laser slab cassettes and flashlamp cassettes have also been built. These are the LRUs that will complete the amplifiers.

Insertion of the assembled LRUs into the BIS requires use of a clean, robotic cart that will transport a massive structure a few hundred meters, keep it clean while traveling through a dirty environment, dock with the BIS accurately, form a seal, lift the structure up to 5

was worked out with the potential users of the NIF. The NIF Programs Review Committee (part of the revamped NIF oversight structure) constituted a Target Physics Review Subcommittee that met in April 2000 [7] to examine this strategy and any new information about target physics. They recommended bringing a portion of the beamlines on line as early as practical, achieving meters, and insert it into place. For maintenance, the robotic cart must also remove LRUs containing items to be repaired off line in the OAB. Figure $5 \mathrm{~d}$ shows the prototype of this vehicle, which has been successfully tested at LLNL over the last several months.

\section{COMMISSIONING NIF}

The entire 192 beam NIF will be completed in FY2008 under the new plan. However the new sequencing of the BIS installation will enable the project to install LRUs and activate beam bundles ( $2 \times 4)$ in a very flexible sequence that can be tailored to optimize early NIF experimental utilization (2005-2008). This socalled Mission First activation strategy symmetry rapidly, and then completing the entire 192 beamlines as the best way to achieve ignition. This can be done with first light on the NIF appearing in FY2004. Figure 6 shows the schedule for this plan and points out when various levels of symmetry would be available.

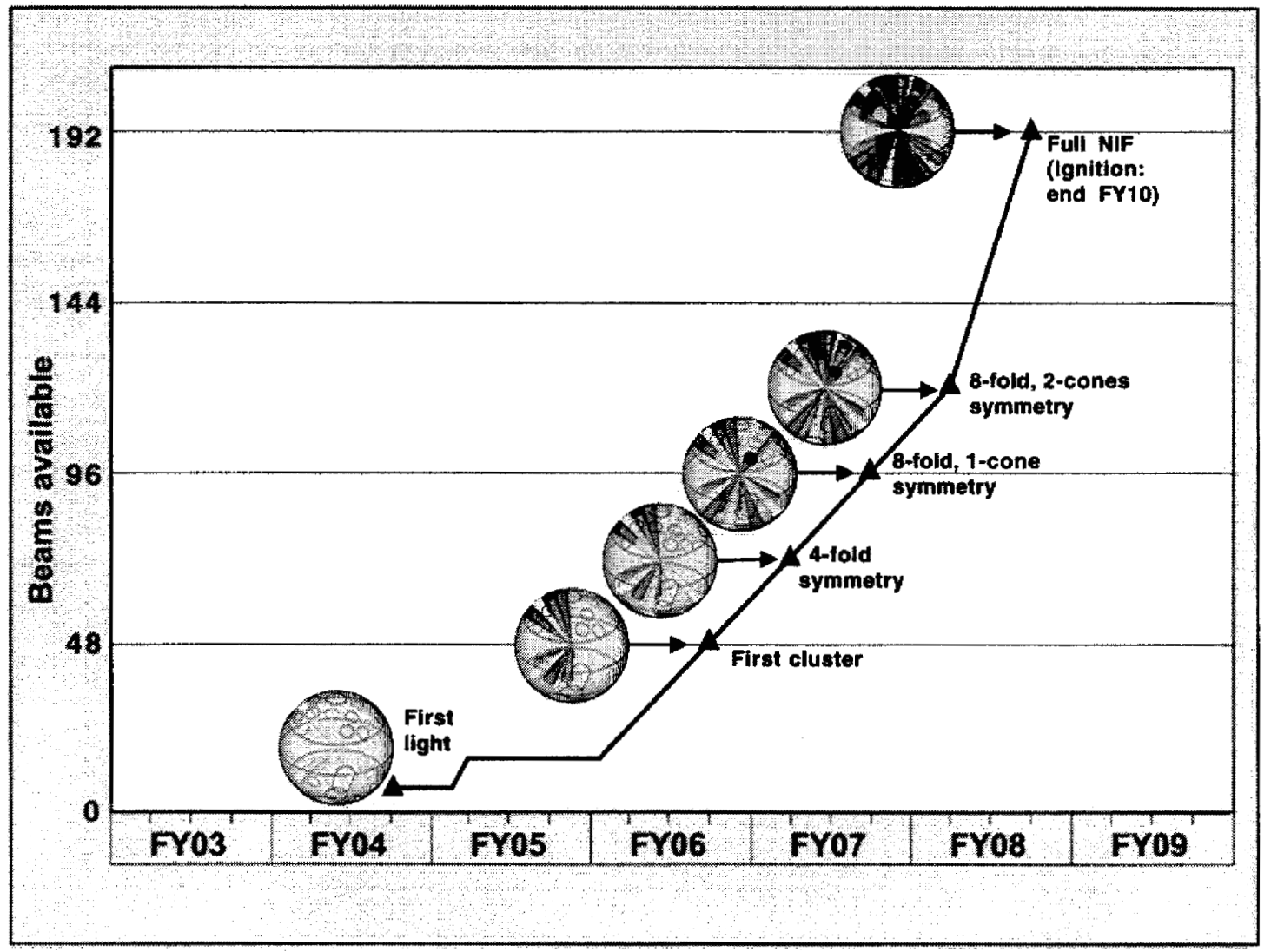

Figure 6. The Mission First commissioning strategy allows many useful experiments during the last four years of NIF Project construction. 


\section{COMMENTS ON THE STATUS OF LASER MEGAJOULE (LMJ)}

(Information about the French program was kindly provided by M. Andre, Project Director of LMJ.)

Ignition remains the main goal of LMJ and the laser energy $(1.8 \mathrm{MJ})$, power $(500 \mathrm{TW})$, and other specifications remain the same as for NIF. The beam aperture is $40 \times 40 \mathrm{~cm}$ as for NIF but the French are planning to build 240 beams rather than 192 in order to meet the specifications with an additional $25 \%$ margin on laser performance. The two designs have other differences in details of the laser design, layout of the beams and illumination geometry as well. France and the United States are jointly developing mass production techniques for laser glass and KDP crystals. However, procurement is being done independently.

One major difference between the programs is that France is constructing the Ligne d Integration Laser (LIL) before proceeding with the LMJ. LIL will be a prototype of one bundle ( $4 \times 2)$ of the beamlines. At $60 \mathrm{~kJ}$ per bundle LMJ will require 30 such bundles to obtain 1.8 MJ. The building for LIL was completed more than one year ago and it is now being outfitted with hardware. The Nova target chamber was shipped to France and is being installed in LIL. The Space frame was completed in June and the first 4 beams will be installed by the middle of 2001. LIL certification would occur at the end of 2001 so that first experiments at $60 \mathrm{~kJ}$ can take place in early 2002. Targets for those experiments are being designed and tested on Omega at the University of Rochester.

The goal for LMJ is to begin construction at the end of 2001. The facility should be fully operational at the end of 2008, about the same time as NIF becomes operational under the new plan.

\section{CONCLUSION}

Both the NIF and the LMJ are on track to become operational in 2008. Both retain target ignition as the main goal and specifications for the two lasers are the same.
The NIF Project has completed the rebaselining activity during the last year. The Project is restructured but still based on the original mission need, specifications and basic design. If the necessary funding is provided, the Project is back on track. The new method of assembly, installation, and integration and the new Mission First commissioning strategy will produce a productive facility very soon.

\section{REFERENCES}

1. National Ignition Facility Justification of Mission Need, Department of Energy, January 15, 1993.

2. National Ignition Facility Primary Criteria/Functional Requirements, NIF-LLNL-93058, L-15983-1, LLNL, Livermore, CA, February 1994.

3. National Ignition Facility Conceptual Design Report Supplement, NIF-LLNL-94-113, L-16973-1, Vol 5, LLNL, Livermore, CA, August 1994.

4. Secretary of Energy Bill Richardson Letter report to Congress on certifying new NIF baseline with attachments, Department of Energy, September 14, 2000 .

5. B. Van Wonterghem, et al., Performance of the NIF Prototype Beamlet, Fusion Technology, Nov. 1994, V26 (N3): 702-707; B. Van Wonterghem, et al., Recent Results of the National Ignition Facility Beamlet Demonstration Project, CLEO 1995, May 22-26, 1995; and Letter report from V. Narayanamurti, Chair ICFAC to Asst. Sec. Reis, Oct. 2, 1995.

6. Report to Congress External Independent Review of the DOE NIF Project, Lockwood Greene Technologies, March 29, 1999, p 3-26 to 3-31.

7. D. Giovanielli, Chair, Target Physics Review Group of the NIF Programs Review Committee, Report of the National Ignition Facility Target Physics Program Review Committee, May 2, 2000.

This work was performed under the auspices of the U.S. Department of Energy by the University of California, Lawrence Livermore National Laboratory under Contract No. W-7405-Eng-48. 